\title{
LA FELICIDAD ESPIRITUAL. \\ Meditación Sentado al PIE DE LA CRUZ
}

\begin{abstract}
International Academy for Philosophy, Liechtenstein/Granada
szalayster@gmail.com

Para Rosario Campos, por revelarme lo que es la verdadera felicidad
\end{abstract}

Resumen

Toda forma de vida espiritual requiere una comprensión filosófica articulada acerca de aquello en lo que consiste la felicidad. Al mismo tiempo, la felicidad es central para la sabiduría y, por ello, para la autocomprensión de la filosofía misma. Como parte de un análisis proto-fenomenológico, rastreo en diferentes idiomas la originaria intuición filosófica sobre cómo la verdadera felicidad difiere de otros fenómenos colaterales. Los términos griego, húngaro, inglés e italiano alumbran algunas características esenciales y trazan el camino para el "análisis fenomenológico" (Wesensanalyse). Sostengo que la felicidad está esencialmente relacionada a la Communio personarum. La felicidad no es una mera "emoción", ni tampoco un "estado anímico" o una "actitud fundamental", sino más bien un "modo de ser". La felicidad no excluye la tristeza, pero es opuesta a la desesperación. Hay una compleja y fundamental relación entre sufrimiento y felicidad que expongo invocando la noción de laetita.

Palabras clave: Felicidad, fenomenología, sabiduría, espiritualidad, sufrimiento

1 Estoy muy agradecido por la conversación con mi querido colega, el Prof. Guillermo Peris Bautista por haberme inspirado y motivado a escribir este ensayo. 


\section{On Spiritual Happiness. A Meditation Sitting under the Cross}

Abstract

Any form of spiritual life requires a philosophically articulated comprehension of what Happiness consists in. At the same time happiness is central for wisdom and thus for the self-comprehension of philosophy itself. As part of a "protophenomenological analysis" I trace back in different languages the genuine philosophical insight on how real happiness differs from related phenomena. The Greek, Hungarian, German, English and Italian terms illuminate some essential features and pave the way for the "phenomenological analysis" (Wesensanalyse). I claim that happiness is essentially related to communio personarum. Happiness is not a mere "emotion", nor is it an "animic state" or a "fundamental attitude" but rather it is a "form of being". Happiness does not exclude sadness but it is opposed to despair. There is a complex and fundamental relationship between suffering and happiness that I expose by recalling the experience of laetitia.

Keywords: Happiness, Phenomenology, Wisdom, Spirituality, Suffering 


\section{Felicidad y filosofía}

La felicidad es una vivencia fundamental de la persona humana. Por su sobreabundancia de sentido su concepto requiere una aclaración constante. Esto es necesario por tres razones: primero, la felicidad de una manera natural requiere reflexión para llegar a su plenitud, es decir, para convertirse en lo que realmente es. Sólo reflexionando podemos hacernos completamente conscientes de qué es, de dónde viene, y para qué nos llama. Segundo, como lo afirma correctamente Aristóteles, todas las personas aspiran a la felicidad. ${ }^{2}$ Para iluminar el fenómeno de la felicidad en un contexto sapiencial podemos acercarnos a la "esencia de la persona humana"; ésta no solamente se revela en la aspiración misma, sino más bien "viviendo" la felicidad plena. Tercero, y como consecuencia de lo dicho, cada cultura tiene una necesidad fundamental para articular filosóficamente, es decir, de forma rigurosa y sistemática, en qué consiste la felicidad, puesto que bajo el término de "cultura" entendemos un abarcador sistema del sentido (Sinnzusammenhang) que distingue las aspiraciones humanas adecuadas - a perfeccionar la naturaleza humana- de las inadecuadas y ofrece caminos acertados y elaborados para realizar dicha vocación del hombre.

Resumiendo lo anterior, podemos afirmar entonces que la relación entre filosofía y felicidad es “esencial” y -segundo-que los dos términos mantienen una interdependencia estrecha. Si la filosofía es incapaz de aclarar y dar un fiel testimonio de la verdadera naturaleza de la felicidad, traiciona su propia vocación, se convierte en un intelectualismo superficial (Glasperlenspiel, un "juego de los abalorios", como lo llama Hermann Hesse) que pasa por alto la pregunta central de la vida concreta del ser humano. Por otro lado, la filosofía no se puede convertir en una mera herramienta externa para desvelar la esencia de la felicidad; la filosofía misma tiene que aportar algo

2 Así lo formula Aristóteles: "Verbalmente hay un acuerdo bastante general, tanto para la generalidad de los hombres y el pueblo de refinamiento superior decir que es la felicidad, e identificar vivir bien y hacer el bien con ser feliz, pero con respecto a lo que la felicidad es que son diferentes, y los muchos no dan la misma cuenta que los sabios." (Ética a Nicómaco, 1095a) 
esencial a la felicidad, si no, la sabiduría queda fuera de las aspiraciones fundamentales del ser humano. Cuanto más feliz es la persona, tanto más quiere comprender en qué consiste su felicidad y cómo puede llegar a su realización plena.

\section{La vida espiritual y la filosofía}

Como indica el título, lo que nos preocupa ahora es la felicidad "espiritual”. Por lo tanto, para dar el siguiente paso es necesario dilucidar la relación entre filosofía y espiritualidad. También entre estos dos términos se descubren lazos estrechos, semejantes a aquellos mencionados anteriormente entre felicidad y filosofía. Filosofar, en sus dos fases fundamentales, es decir, como búsqueda y como transmisión de la sabiduría (cfr. Platón, República: VII), es un elemento básico de la vida espiritual. Las verdades que se revelan como una intuición en el alma, para que se desvelen de forma plena y para la comprensión plena de su sentido más profundo, nos invitan a un trabajo sistemático, metodológicamente riguroso y dialógico. Esta forma de reflexión es propia de la filosofía y en las diversas etapas de esta noble tarea se enfrenta con distintos desafíos. Empezando con la formulación fiel y adecuada de las intuiciones, a través de la investigación, qué verdad revelan a la luz de la tradición clásica de la filosofía, hasta la definición del acto concreto de "dar testimonio" en el mundo de la vida (Lebenswelt), tenemos que dar varios pasos para realizar la verdad de nuestra intuición originaria. En este proceso se desarrolla la vida espiritual.

En segundo lugar, no es solamente que la filosofía forma parte de la vida espiritual, sino que es justamente la ciencia más adecuada para revelar la misma naturaleza del alma. En este sentido la filosofía tiene una tarea mucho más noble, profunda y abarcadora que la psicología, puesto que ésta se dedica más bien a la investigación de los procesos psicológicos, sus relaciones y el conjunto de sus resultados, mientras que la filosofía investiga el alma entera, no solo en sí misma y como integridad, sino en su relación con todo aquello que se distingue de ella, con todo lo que no-es-alma. Por ello la filosofía 
pretende desarrollar una reflexión metafísica y más específicamente antropológica, una investigación fundamental en la cual se integra la psicología como estudio específico.

En tercer lugar, la filosofía es ya siempre una "preocupación del alma”. ${ }^{3}$ La sapiencia y el trabajo filosófico, sea investigación, enseñanza, escritos y, sobre todo, la reflexión como una contemplación entregada a la verdad que se revela, promueve el "bien supremo" del alma, puesto que se dedica a dilucidar lo bueno y su más pleno reconocimiento. La verdadera filosofía, mientras sin duda alguna aspira, y está transida por el deseo de descubrir y explicitar la verdad, no solamente implica una adquisición del conocimiento evidente y seguro, puesto que el filósofo no quiere simplemente poseer el conocimiento sapiencial o aplicarlo bien, sino vivirlo plenamente. Este “vivir la verdad”, este "dejarla que sea vigente” o, lo que es más: "dar testimonio de ella", son funciones tan elementales de la filosofía como lo que suele ser casi exclusivamente acentuado en la Modernidad, a saber, la búsqueda de la verdad (o peor aún, de una verdad subjetiva).

Justamente porque la filosofía es una epimelesthai, ${ }^{4}$ y más específicamente una "preocupación por el alma”, puede convertirse en una

3 Veáse el concepto fundamental de Platón en la interpretación de Jan Patocka (1996) y la Apología de Sócrates (29e). Las ideas de Platón encontraron un eco fuerte dentro del Cristianismo. Un ejemplo especialmente bello es el texto del Gregorio de Niza, De virginitate. En este tratado él pone el ejemplo de su propia hermana delante de sus lectores como un modelo de quien se preocupó por su alma. En el cápitulo 12 analiza el diálogo escrito por Lucas sobre los dracmas perdidos (LC 15, 8-10) y enseña que a través de un cierto ascetismo corporal y espiritual se logra llegar a la vida eterna. Él da una interpretación propiamente cristiana sobre la preocupación por el alma, cuando subraya qué destacada importancia tiene esta praxis en la recuperación de la imagen de Dios en nosotros. Así la persona se hace merecedora de la felicidad eterna. (Cfr. Gregorio de Niza, 2009). De manera muy semejante trata Bernardo de Claraval (1999) la noción de conocerse en su sermón 20.

4 Véase el diálogo Alcibíades de Platón, 127d. Michel Foucault da una interpretación notable de la expresión platónica: "Epimelesthai expresses something much more serious than the simple fact of paying attention. It involves various things: taking pains with one's holdings and one's health. It is always a real activity and not just attitude. It is used in reference to the activity of a farmer tending his fields, his cattle, and his house, or to the job of the king in taking care of his city and citizens, or to the worship of ancestors or gods, or as a medical term to signify the fact of caring. [...] The rest of the text is devoted to an analysis of this notion of epimelesthai, "taking pains with oneself". 
“preocupación espiritual” y en un cuidar las almas. Cuidar el alma del otro es una guía filosófica motivada y llevada a cabo por amor. Esta guía, por cierto, nunca es unilateral, puesto que cada persona que verdaderamente guía, ya es guiada. Estar guiado significa, antes que nada, que el filósofo se concibe dentro del contexto de "servicio a la verdad”. En segundo lugar, la persona que recibe las indicaciones del filósofo siempre aparece delante de él como una realidad autónoma cuyo sentido es inagotable y por tanto incomprensible. ${ }^{5}$ El filósofo tiene que ajustar, sin embargo, cada paso que da a esta “entidad” libre, que se revela como la Infinita Realidad para él, en la cual unidos en el diálogo como compañeros de viaje están llamados a orientarse. ${ }^{6}$

It is divided into two questions: What is this self of which one has to take care, and of what does that care consist?

"First, what is the self (129b)? Self is a reflective pronoun, and it has two meanings. Auto means "the same", but it also conveys the notion of identity. The latter meaning shifts the question from "What is this self?" to "What is the plateau on which I shall find my identity?" Alcibiades tries to find the self in a dialectical movement. When you take care of the body, you don't take care of the self. The self is not clothing, tools, or possessions. It is to be found in the principle which uses these tools, a principle not of the body but of the soul. You have to worry about your soul - that is the principle activity of caring for yourself. The care of the self is the care of the activity and not the care of the soulas substance. [...] The second question is: How must we take care of this principle of activity, the soul? Of what does this care consist? One must know of what the soul consists. The soul cannot know itself except by looking at itself in a similar element, a mirror. Thus, it must contemplate the divine element. In this divine contemplation, the soul will be able to discover rules serve as a basis for behaviour and political action. The effort of the soul to know itself is the principle on which just political action can be founded, and Alcibiades will be a good politician insofar as he contemplates his soul in the divine element" (Martin, 1988: pp.16-49 y Foucault, 1994).

5 Uso la expresión "incomprensible" en el sentido analógico en que la aplicó san Agustín en contraste con lo que es "entendible" con respecto a Dios: si lo comprendes, no es Dios. Aunque sin duda alguna, metafísica y antropológicamente entendemos y captamos rasgos esenciales de la realidad del ser humano como tal, nunca logramos una comprensión plena que abarca todo el sentido de su ser y su ser-así. Comprender, es decir, entender en toda su complejidad la realidad concreta de "esta" persona (quidditas), es aún más imposible.

6 Un bello ejemplo es el encuentro entre el piloto y el principito en el libro de SaintExupéry. Los dos amigos, perdidos en el desierto, descubren a través de su amistad su vocación en su propio mundo. Así, enriquecidos por una vivencia que los remite a un sentido transcendente y objetivo de su vida, regresan a su hogar. 
La filosofía, entonces, no busca solamente el bien de la propia alma, sino al mismo tiempo el bien de la persona concreta (filósofo) y el bien de un sí mismo (self) pleno; buscando el bien del alma como tal, entonces la filosofía ya siempre surge de una "preocupación por el alma” de "todo" ser humano. Por lo tanto la filosofía, en su fase de búsqueda, ya se caracteriza por una dimensión elemental de comunión. Aunque, por el estado actual de la cultura nos puede resultar sorprendente, el oficio del sabio (cfr. Calder, 2010) es inseparable de la vida en comunión. ${ }^{7}$ Tanto los ejercicios espirituales (cfr. Hadot, 1987) como las experiencias concretas de una vida compartida (convivencia) son indispensables para que la realidad que se revela en las vivencias llegue a ser reconocida, justamente como una "verdad en sí misma" que trasciende las dimensiones de la vivencia de un sujeto. La vida en comunión no se relaciona con la filosofía solamente por el hecho de que la filosofía no busca verdades meramente subjetivas o relativas, sino objetivas y universales - a pesar de su modo de darse en las vivencias individuales.

La filosofía está completamente incrustada en la vida comunitaria: parte de allí y llega a su plena expresión en la misma comunión (cfr. Grygiel, 2002). El mismo mundo de la vida (Lebenswelt), (cfr. Husserl, 1936), en cuanto es siempre ya compartido con personas humanas y divinas, es decir en cuanto se verifica como comunión, es lo que nos invita e inspira a reflexionar filosóficamente; por otra parte, en la entrega plena de la persona, en regalarse al otro llega la sabiduría a su perfección. Sin amar a la otra persona concreta, es decir, sin participar en lo bueno, bello, y verdadero dentro de la comunidad concreta con ella, la filosofía se atasca a medio camino, donde el conocimiento es puro poder ${ }^{8}$

7 Véase especialmente la Carta VII de Platón: “Desde luego, no hay ni habrá nunca una obra mía que trate de estos temas; no se pueden, en efecto, precisar como se hace con otras ciencias, sino que después de una larga convivencia con el problema y después de haber intimado con él, de repente, como la luz que salta de la chispa, surge la verdad en el alma y crece ya espontáneamente" (341c).

8 Véase la discusión de Sócrates con Trasímaco en la República: "Pues bien, esto es, hombre excelente, lo que digo que en todas las ciudades es de igual modo justo: lo que conviene al gobierno establecido. Él tiene elpoder, de donde se sigue, para quien reflexiona correctamente, que en todas partes es justo lo mismo, a saber, lo que conviene al más fuerte" (República, I, 339a). 
sin servicio o respuesta a la realidad que se nos pone delante y entrega verdadera que implica sacrificio. ${ }^{9}$

\section{La protofenomenología de la felicidad}

Bajo el término "protofenomenología" entiendo una propedéutica filosófica que antes de la descripción de los fenómenos, basada en el 'análisis de esencias' (Wesensschau), aclara la relación fundamental del sentido, en la cual el fenómeno aparece. La protofenomenología se enfoca en el modo de aparecer, y así abre caminos para el trabajo fenomenológico sacando a la luz la esencia del fenómeno. Concentrándonos ahora en la felicidad, tomamos como punto de partida la forma más cercana y más general de la apariencia del fenómeno: su expresión lingüística. No voy a indagar en las explicaciones etimológicas, sin embargo me gustaría subrayar que cada idioma, como sistema de signos, refleja de manera distinta la experiencia básica del ser humano con respecto a la felicidad, distinguiendo desde puntos de vista diferentes la verdadera felicidad de los fenómenos semejantes y sus expresiones deficientes.

\section{a. Felicidad (doldogság)- procurarse la felicidad (boldogulás)}

Por orden de explicación, empezando con lo más básico, es bueno tomar como punto de partida la riqueza del idioma húngaro, fijándonos en la diferencia entre 'boldogság' (felicidad) y 'boldogulás'

9 El sacrificio es parte esencial de cada respuesta auténtica de filosofía a la realidad. La realidad, en cuanto objetiva, (más que nada manifestada en y trasmitida por la otra persona), requiere una respuesta que implica un esfuerzo para superarnos. La respuesta debida a la realidad exigente que se revela delante de una mirada filosófica (que busca la sabiduría y está dispuesta acogerla) no es otra sino la trasformación de la persona: conversión. La conversión filosófica, la metanoia es un sacrificio en cuanto es una afirmación de la realidad como una donación buena. El reconocimiento personal de este carácter (santo) repercute en la mirada del filósofo hacia sí mismo. El acto que sigue a esta mirada es el sacrificio: reconocer en sí mismo lo que es santo y actuar según esto dejando fuera todo el resto que no merece tal afirmación. 
(procurarse la felicidad). La expresión boldogulás es un substantivo derivado de un verbo, y como tal, pone de relieve la actividad personal respecto a la felicidad. La persona, que se concibe dentro del ámbito de boldogulás, busca su propia felicidad a través de solucionar problemas y vencer dificultades. El concepto de boldogulás es, por lo tanto, una cierta forma activa de "procurarse la felicidad", que no es tanto un "estado de ánimo", y mucho menos un "estado del alma”, sino más bien una determinada forma de vida, en cuyo contexto el "individuo" 10 realiza sus intenciones con muchos esfuerzos en un ambiente no amistoso y problemático, y llegando a tener éxito. Es significativo que concebir el resultado de "procurarse la felicidad" como felicidad, sea sumamente opuesto al pensamiento personalista de Gabriel Marcel, puesto que según esta deficiente antropología perjudicada por la falta de distinción filosófica y existencial entre "ser" y "tener", ${ }^{11}$ la persona se mide por logros, resultados y éxitos en el sentido de "somos lo que hacemos". Delante de esta actitud fundamental, lo que aparece como felicidad no es más que la mera

10 Digo "individuo", contrastando con el concepto de la persona, para marcar la tensión con respecto al concepto del sujeto de la felicidad en la época premoderna y moderna.

11 Es necesario recordar aquí a la distinción entre être y avoir de Gabriel Marcel. Marcel demuestra a través del ejemplo del cuerpo la diferencia entre lo que somos y lo que tenemos. Aparentemente esta distinción es muy obvia, sin embargo hay casos más complejos sobre los cuales es necesario recurrir a una aclaración filosófica. Mi cuerpo es por un lado un objeto en el mundo exterior -solo que me pertenece, yo lo poseo-, por otro lado se diferencia radicalmente de todos los demás objetos. Al mismo tiempo tampoco podemos afirmar que "soy mi cuerpo" puesto que perdiendo un miembro no seré menos persona. Es también verdad que, de alguna manera, soy dueño de mi cuerpo. Este ejemplo demuestra que en realidad se trata de dos actitudes diferentes, que caracterizan tanto la relación conmigo mismo como la relación con los demás. Así se puede concebir a la otra persona desde un punto de vista externo según su instrumentalidad como algo útil y agradable, fijándonos en sus valores exteriores e interiores o, por el contrario, según lo que es por sí mismo y en sí mismo. Mientras en el centro de la primera actitud se encuentra lo que Marcel llama assimiler, la segunda actitud nos permite acercarnos al otro en el encuentro no por aspectos exteriores sino desde el ser; tal visión implica, en vez de assilimer, una verdadera participación (cfr. Marcel, 1935). A mi modo de ver, la posibilidad de las dos actitudes mencionadas por Marcel también se da con respecto a "mí mismo"' Esto se expresa de varias formas. Un destacado ejemplo es que se puede mirar el "sí mismo" de mi biografía, por un lado, como viviendo en una época entre nacimiento y muerte o, por otro, como lo que "participa" en el Ser (cfr. Marcel, 1959: pp.35-37). 
satisfacción por una auto-proyección bien realizada: es un mero "estar" contento que nunca llega a la altura de "ser" feliz.

Es una tarea exigente, y a su vez propia del filósofo, vislumbrar que la verdadera felicidad no se puede identificar con la actividad de autorealización exitosa, puesto que es un rasgo esencial de la felicidad que "nos llena": más que llegar nosotros a la felicidad, la felicidad llega a nosotros. La aceptación de esta vivencia es un acto radicalmente diferente de lo que denominamos arriba como "procurarse la felicidad". Para captar bien esta diferencia es necesario aclarar la relación entre la felicidad como "estado de ánimo" y la de procurarse la felicidad como "actividad". Desde el punto de vista lógico podemos afirmar las siguientes tesis: (1) La felicidad (boldogság) no es idéntica a procurarse la felicidad (boldogulás), pero (2) tampoco es independiente de ella. (3) La relación entre felicidad y procurarse la felicidad no es una relación causal.

Esta última constatación se explica por el hecho de que la felicidad no es un resultado natural del "bienestar" externo, puesto que entre bienestar y felicidad se abre un hueco para el juicio libre sobre el valor de la situación actual, vivida internamente. La felicidad sin designarla como un término meramente subjetivo-implica un juicio de valor (Werturteil) con respecto a nuestro destino: de ninguna manera es una mera emoción. Sin duda alguna este "juicio de valor" (Werturteil) no es del todo independiente de la situación vital concreta en que uno se encuentra. Las relaciones entre situación y respuesta al valor (Wertantwort) que incluyen un "juicio de valor" (Werturteil), pueden resultar muy sorprendentes: en el caso de las almas nobles y sencillas (como por ejemplo la de santa Edith Stein) las más grandes dificultades y el abandono más doloroso coincide con el descubrimiento de la verdadera fuente de la felicidad. La realidad de esta felicidad, aunque se desvela en una experiencia dentro del flujo del tiempo, su esencia, o mejor, su fuente de origen, permanece intacta de los cambios circunstanciales que se producen en el alma. La vivencia concreta de la felicidad es siempre muy subjetiva y, si es una felicidad profunda, es más probable que su verdad y su sentido específico se ajusten de tal modo a la realidad concreta de la persona que lo vive, que los límites para comunicarlo y compartirlo 
aparecen con toda claridad. Sin embargo, la realidad que transmite el origen de la felicidad es una esencia inmutable y especialmente inteligible; según la comprensión de la fenomenología elaborada por Adolf Reinach (1951), Dietrich von Hildebrand, Alexander Pfänder y Edith Stein, posibilita un análisis fenomenológico y una contemplación sapiencial.

La unidad y, al mismo tiempo, la diferencia entre boldogulás (procurarse la felicidad) y boldogság (felicidad) se capta más claramente con respecto al contraste entre "actividad" y "contemplación". ${ }^{12}$ Para ver esto en detalle hace falta una muy breve aclaración de los conceptos claves. Primero tenemos que llamar la atención sobre la diferencia entre acto y actividad, y después tenemos que hacernos conscientes de que la contemplación no es un pensamiento discursivo.

Como "procurarse la felicidad" es obviamente una actividad, se podría pensar que "ser feliz" presupone una pasividad completa. Vivir la felicidad, sin embargo, incluye varios actos emocionales, intelectuales y espirituales, puesto que es más que nada una respuesta al valor (Wertantwort) (cfr. Hildebrand, 1971). Uno de estos actos $-\mathrm{y}$ cuya relación con la felicidad es la más estrecha según la tradición clásica-, es la contemplación. La contemplación es una reflexión especial sobre un contenido de la conciencia; es una forma "activa" de "dejar" desfilar el fenómeno evocado delante de los “ojos interiores" de la conciencia, desvelándolo para que se revele (selbstoffenbaren) a sí mismo y en sí mismo. La contemplación se distingue sobre todo del "pensamiento discursivo" (cfr. Szalay, 2008) ${ }^{13}$ en el hecho de que no mira al fenómeno desde un punto de vista específico concentrándose cada vez en otro aspecto de la apariencia, sino que conlleva una apertura por parte del receptor que permite aceptar y reconocer la realidad revelada en su plenitud. La contemplación indaga y permanece (dwelling) en el sentido del fenómeno que se da a sí mismo

12 Por razones editoriales no puedo dedicar más atención, en este contexto, a la pregunta ciertamente muy interesante sobre la relación entre praxis y teoría filosófica. Me limito a un aspecto de esta discusión, que es relevante en nuestro contexto, reconociendo que hace falta una reflexión más abarcadora sobre el tema.

13 Aquí explico con más detalles la unidad y la diferencia entre reflexión, meditación y contemplación. 
(Selbstgegebenheit) en su totalidad. La contemplación supera el nivel de un pensamiento que avanza de punto a punto buscando respuestas a preguntas específicas, y requiere una activa permanencia en la actitud de apertura, tanto intelectual como espiritual, para recibir el sentido cada vez más profundo, avanzando de un nivel a otro, hasta el propio origen de su donación. La recepción atenta y bien enfocada requiere una serie de actos y una activa educación y formación de la "actitud fundamental" (cfr. Crespo, 2007) que la hace posible. Además, como la contemplación es el nivel más alto del "pensamiento", presupone ya ciertas formas de reflexión sobre la concreta vivencia misma; tal reflexión en el ámbito filosófico incluye ciertamente un “análisis eidético" (cfr. Husserl, 1929 y Seifert, 1977), o mejor dicho, una investigación del sentido y de la esencia del fenómeno en cuestión. Es importante ver que la filosofía no se agota en tal investigación "activa", sino que requiere un paso más de abandono, un paso de suspender la búsqueda, siendo capaz de permanecer de manera gozosa en la verdad en cuanto ésta se revela a sí misma.

Resumiendo: la felicidad no es un mero "estado de ánimo" que surge como una consecuencia o que es causada por un acto o actividad; la felicidad que nos llena es más bien un "regalo" que aparece a la espalda de tal actividad (auf dem Rücken des Aktes) de procurarse la felicidad (cfr. Hildebrand, 197: cap.5), en el sentido de preocuparse por sí mismo, por el alma. En este sentido requiere aspirar a la felicidad teniendo siempre en cuenta su propia naturaleza. Tal aspiración se desarrolla en dos ámbitos: por una parte estamos llamados a establecer las "externas" condiciones de posibilidad de la felicidad. Por otra parte lo que es "vivir la felicidad" requiere unas condiciones internas de posibilidad de la felicidad. Esto último no es nada menos que la praxis filosófica y religiosa de epimelesthai, que desemboca en la “vida espiritual”. La vida espiritual está, a su vez, basada y llega a su plenitud en la comunión concreta de las personas. 


\section{b. Glück (szerenczse)- Glücksleigkeit (eudaimonía)}

¿Qué significa exactamente que la felicidad no es tanto la consecuencia de "procurase la felicidad", sino más bien un regalo? Para captar mejor la naturaleza de la felicidad como un "don de sí mismo" es conveniente profundizar en la diferencia entre las expresiones alemanas Glück y Glückseligkeit. La palabra Glück da lugar a una interpretación de la felicidad que la liga con la suerte. Glück refleja una visión en la cual la felicidad es tan independiente de cualquier actividad respeto a "procurarse la felicidad" que aparece como un fenómeno sin una causa identificable. Glückseligkeit, por otro lado, es la expresión equivalente en alemán a la famosa y (con razón) muy debatida eudaimonía de Aristóteles. La expresión alemana destaca dos aspectos esenciales para entender la felicidad. Por uno lado, acentúa la dimensión voluntaria de vivir la felicidad y, por otro lado, aparece como un conjunto de Glück (felicidad) y selig (bienaventurado, dichoso) poniendo de relieve la relación entre felicidad y santidad. La felicidad como Glückseligkeit en contraste con el mero Glück, no es un estado de ánimo motivado por unos eventos, sino que revela la naturaleza del alma en su plenitud como un estado de santidad (Seligkeit) que se vive como felicidad.

No es mi tarea ahora señalar los peligros que conlleva el concepto de eudaimonía aristotélica, puesto que muchos fenomenólogos realistas como Edith Stein, Dietrich von Hildebrand, Max Scheler y, siguiendo sus huellas, más recientemente Karol Wojtyla y Josef Seifert, ya advirtieron de la reducción que surge de esta visión cosmológica. Me gustaría llamar la atención sin embargo sobre el sentido original de la expresión, según el cual la felicidad es "estar dominado” y poseído por un daimon (espíritu) bueno. En este concepto de la felicidad se verifica una intuición propia de cada auténtica vivencia de la felicidad: la felicidad conlleva una transformación radical del alma que la afecta en su misma esencia. El hombre feliz es un nuevo hombre. Stein llama a dicho cambio Wesensveränderung. Como veremos en la investigación fenomenológica, la felicidad espiritual es un nuevo comienzo de la vida espiritual que no sólo potencia todas las facultades sino que las lleva a su plenitud. 
c. Joy-pleasure-cheerfulness (alegría-gozo-ánimo levantado)

Hasta este momento nos hemos dedicado a la apariencia del fenómeno. En un siguiente paso nos centraremos en el modo concreto de vivirlo. Estamos buscando la respuesta a la pregunta sobre qué relación tiene la felicidad con la respuesta emotiva como alegría (joy), con el gozo (pleasure) y con el estado de ánimo como buen genio o incluso jocosidad (cheerfulness), puesto que la felicidad suele confundirse con ellos con tanta frecuencia, como también se suele afirmar falsamente que la felicidad no tiene nada que ver con ellos.

Empecemos a ser conscientes de las diferencias. El puro gozo no se puede identificar completamente con la felicidad. Más allá de los argumentos clásicos que provienen de la filosofía de Aristóteles podemos mencionar otros dos aplicando el método fenomenológico. Primero, puesto que se goza siempre de algo en concreto, como el gozo es un afecto directo del objeto intencional, lo que causa el gozo es siempre un objeto específico. Más específicamente, el gozo hace referencia a unas características determinadas del fenómeno, que son gozosas, y por lo tanto pueden causar un deleite en el sujeto siempre que éste tenga la apertura y la sensibilidad hacia tal propiedad. Hasta que tal propiedad se presente en su conciencia percibida con la misma actitud, el juico de valor (Werturteil) respectivo sigue vigente y el gozo se mantiene por la decisión voluntaria de dejarse llevar por el fenómeno en cuestión. En cuanto uno goza algo, lo posee respecto de su propiedad gozosa.

El "objeto intencional" de la felicidad, que es al mismo tiempo su causa, no se puede definir e identificar de la misma manera que en el caso del gozo; no es una propiedad de una cosa, ni siquiera si dentro de la vivencia tal fenómeno aparece en relación (y directamente antes de) la experiencia de la felicidad. Dicho de otra manera: a lo que la felicidad hace referencia como su causa siempre va más allá de los "objetos" concretos; la felicidad se refiere a la realidad como tal. Es cierto que la felicidad incluye y conlleva un juicio de valor (Werturteil), que trata de la naturaleza de la realidad que se reveló al sujeto gracias a una o varias vivencias concretas.

En segundo lugar, que la realidad de la felicidad como tal subsista aunque la felicidad como vivencia concreta, como experiencia 
subjetiva, se reduce a un tiempo concreto, se debe sólo y exclusivamente a las limitaciones del receptor, de la persona humana concreta y no es consecuencia de la naturaleza del "objeto". La felicidad tiende de manera inherente a mantenerse sin límites temporales. Dada la naturaleza del "objeto intencional" de la felicidad, la relación es radicalmente distinta de la relación que se da en el gozo: no es poseer sino más bien, como lo veremos más adelante, "estar delante de algo" o, mejor dicho, de alguien.

A pesar de la diferencia argumentada anteriormente, el hecho de confundir el gozo con la felicidad no carece de fundamento alguno. La persona feliz - muy parecida a la que goza - tiene una actitud positiva con respecto al "objeto". Más específicamente se caracteriza por una apertura aún más grande, por una "actitud fundamental” absolutamente positiva: la felicidad es un "si" ante la realidad. Esta "actitud fundamental" (Grundeinstellung) también permite de forma análoga al gozo, un "dejarse llevar”, un desprenderse y abandonarse a sí mismo. La persona feliz mora, permanece delante de su objeto dejando al lado sus preocupaciones, sus preguntas con respeto al futuro, y se pregunta sobre la contemplación del origen de su felicidad. Es más: la persona dichosa, en su contemplación, recorre las dimensiones de la realidad con gozo, aunque nunca pierde la vista de la totalidad como tal. Por esto, cuando la felicidad llega a la plena conciencia, es una afirmación de la creación misma, es decir, de todo lo que existe como fundamentalmente bueno.

En vista de lo dicho, es relativamente fácil aclarar la relación entre alegría y felicidad, puesto que la alegría como "emoción” se limita necesariamente a un concreto tiempo transcurrido. La diferencia se hace más patente teniendo en cuenta que lo opuesto a la alegría es "la pena" que uno siente, mientras que la felicidad no excluye y no es irreconciliable con la tristeza. No debería faltar la pena del mundo emocional de la persona feliz, puesto que ni su juicio en referencia a la realidad como tal, ni su modo de desprenderse de sí mismo, ni su auto-donación, y mucho menos su actitud fundamental, excluyen que todas las partes relevantes de la realidad evoquen en la persona feliz una respuesta adecuada a la propia naturaleza de las cosas y acontecimientos. Justamente por la base firme que se nos da en 
la felicidad, estamos capacitados para mirar los eventos y acontecimientos que, con razón, provocan enorme tristeza en nosotros. La persona feliz no tiene por qué cuidarse y defenderse de lo dramático de la vida, puesto que ya no confunde lo dramático con lo trágico; su mundo emocional no está encerrado, no busca un asilo en la ataraxia, sino que está dispuesta a percibir y enriquecerse con todos los matices emocionales de lo que se desvela como real.

No obstante esto, la expresión más adecuada de la felicidad en cuanto "emoción" es sin duda alguna la alegría, como argumentaremos adelante, en la medida que la felicidad es verdaderamente una cierta forma de existir en un "estar juntos", es decir, es la forma de vivir la communio personarum, pues cuando uno es consciente de la presencia de la persona amada, lo que siente de forma natural y necesaria es una alegría desbordante.

Veamos, en tercer lugar, qué distingue la alegría de la felicidad. La alegría, y su opuesto, la tristeza como un "estado de ánimo", se diferencian completamente de las emociones concretas, engendradas por una causa determinada y basadas en una percepción concreta. El ánimo elevado, jocoso y alegre, y la tristeza, en cuanto son estados de ánimo, nos abren una ventana a la realidad. El actual "estado de ánimo" que uno tiene deja su huella en cada experiencia o, dicho de otra manera, filtra lo que percibimos. El alma siempre se encuentra en un estado determinado, nunca se encuentra en un estado neutro: se abre más a ciertas unidades de sentido y es menos perceptible en relación con otras facetas del mundo que no son tan adecuadas a su sensibilidad actual. Dichos sentidos que aparecen en el horizonte del sentido no llegan con la misma facilidad (e intensidad emocional) a la conciencia.

Los “estados de ánimo" se alternan, y es difícil llegar con claridad a la causa del cambio. Detrás de cada cambio hay un resultado de un conjunto de procesos psíquicos; parte de ellos sucede en la dimensión de la conciencia que sólo se abre por una investigación conceptual, por esfuerzos específicos aplicando ciertos métodos de introspección. Esto no quiere decir ni que no podamos contra-actuar voluntariamente en relación con los estados de ánimo, ni mucho menos que se nos escapen totalmente, puesto que se expresan 
y surgen a la superficie en el ámbito de la reflexividad. Una de las características más maravillosas del alma es justamente que se puede establecer una relación libre con sus estados, es decir, que en el caso dado, cuando logramos ver que son inadecuados, se pueden rechazar o modificar los propios "estados de ánimo". (Por ejemplo en el caso de Schadenfreude, que designa el sentimiento de alegría creado por el sufrimiento o la infelicidad del otro.)

La diferencia más tajante entre la felicidad y los estados de ánimo es que la felicidad bien vivida descubre su origen como eterno. Nos puede parecer que su duración es siempre limitada; sin embargo, este descubrimiento nos remite a una introspección, a una revisión de nuestra conciencia, puesto que la limitación -como argumenté con anterioridad-surge de aquí. La verdadera felicidad se desvanece cuando la persona que la vive deja de percibir su verdadera fuente. En la luz de esta intuición se puede afirmar que la vivencia de la felicidad - a pesar de las apariencias- tiene una estructura radicalmente diferente a los "estados de ánimo" (las emociones o el mismo gozo).

En segundo lugar, la felicidad difiere de los "estados de ánimo" porque no caracteriza al alma sólo por un aspecto específico (en cuanto Stimmung), sino por completo, en la totalidad de su ser. Por esto la felicidad es un "estado del alma"; es la forma del alma en su plenitud, en su ser pleno.

La felicidad no es irreconciliable ni con la alegría ni con la tristeza. Tanto la alegría como la tristeza tienen su propio tiempo y lugar. Mientras la alegría más bien abre una ventana a la realidad fuera de nosotros, la tristeza del alma, sufriendo, invita a una mirada aguda hacia el alma misma, nos empuja a ir a lo más profundo del mundo interior. Ambas, alegría y tristeza, revelan aspectos distintos de vivir la felicidad plenamente. Por supuesto esta riqueza no excluye que de vez en cuando -justamente para mantener el pleno sentido- debamos luchar contra los excesos de la alegría que tiende a satisfacerse con lo superficial, lo que nos ofrece una percepción del mundo que no se da cuenta de la inmensidad del sufrimiento que nos rodea. Por otro lado, a la luz de la realidad plena que nos revela la felicidad, debemos cuidarnos de la tristeza que fácilmente nos conduce a la desesperación que finalmente destruye la comunión. Esta cautela no 
significa otra cosa que vivir tanto la tristeza como la alegría según su verdad propia, es decir, afirmando con toda apertura la realidad que nos trasmiten, siempre conscientes de su origen. Fijándonos en su origen, es decir, en aquello que se revela en cada percepción verdadera de la realidad, podemos ir más allá de lo que se presenta como mundo en un cierto "estado de ánimo". No obstante, quien no conoce la tristeza profunda se hace una imagen de la felicidad igualmente borrosa, como quien la confunde con la alegría.

\section{La fenomenología de la felicidad}

Con el análisis proto-fenomenológico hemos circunscrito el fenómeno de la felicidad. Como resultado podemos afirmar que la felicidad no es una actividad, aunque presupone ciertos actos, y vivir la felicidad plenamente incluye varios actos. También podemos constatar que la felicidad no es una emoción ni un estado de ánimo, aunque presupone una cierta "actitud fundamental”; en sí misma no es una actitud, puesto que no se refiere a la relación entre objeto y sujeto, sino que caracteriza al alma como tal. La distinción entre "estado anímico" y "estado del alma" pone de relieve que la vivencia de la felicidad inspira al alma una existencia radicalmente renovada, que a su vez da lugar a una nueva vida espiritual.

Para revelar más el fenómeno de la felicidad ahora tenemos que especificar cuál es el origen de la felicidad, cuál es su verdadero "objeto intencional”. También en este sentido tenemos que seguir la ruta tomada en la investigación preparatoria. Comparándola con los fenómenos semejantes, se aclaró que el objeto de la felicidad no es un objeto concreto y temporal del mundo de la vida. Por otro lado, ya Aristóteles afirmó que la felicidad no busca ningún fin fuera de sí misma. En suma: no somos felices ni a causa de algo ni para algo.

No obstante, la felicidad no es un disfrute del alma de uno mismo. Como hemos visto la felicidad no es un gozo especial de algo, puesto que no incluye un juicio sobre un fenómeno (ni siquiera del alma), sino más bien sobre la realidad como tal. Sería absurdo pensar que la persona feliz es feliz por su alma, y que no es algo distinto del 
alma lo que engendra su felicidad. El juicio que incluye la felicidad se fundamenta en la experiencia en la cual la realidad se revela como completa, plena, y se refiere, se afirma y se verifica en verdades que surgen de dicha revelación. Es importante ver que, al contrario de la fuerte influencia del estoicismo hasta nuestros días, la "totalidad de la realidad" relevante para la vivencia de la felicidad no se nos da en una vivencia como experiencia cósmica, es decir, no es una revelación del cosmos como un orden inteligible del mundo, sino que, más bien, el lugar propio de la vivencia de la felicidad es el encuentro personal. La felicidad es un estado del alma y aparece no debido a algo, sino suscitado por "alguien", por una persona concreta, en cuya presencia nuestra alma llega a su plenitud.

El nacimiento de la felicidad es el encuentro personal, en cuanto que éste es una libre revelación de la persona en la contemplación, que no está limitada por juicios anteriores, ni por falta de apertura; es la persona misma que logra trascender la mirada a la realidad como completa. Por lo tanto - como los clásicos afirman, los padres de la Iglesia precisan y algunos modernos completan-, la persona, tanto en el nivel ontológico como epistemológico, tiene un rango especial. La persona no es sólo parte del cosmos, sino que ella misma es un micro-cosmos: toda la realidad se refleja en ella (cfr. Pico de la Mirandola, 1984; Nemesio de Emesa, 1975). La persona humana, sin embargo, más allá de ser un mero reflejo, por su ser y realidad que recibe como donación, también expresa y manifiesta la realidad en su esencia; es capaz de transmitir lo que transcurre y ordena toda la realidad. La realidad trascendente que la persona humana transmite por su ser y por sus expresiones que resurgen de su naturaleza perfeccionada, es nada menos que el amor divino que impregna al hombre y desborda.

Es por esto que la felicidad es una verdadera communio personarum, es decir, un estado característico de la comunidad en amor; no es solamente una comunidad en cuanto participación en el amor, sino también la respuesta de la persona con todo su ser en el encuentro con la realidad como completa. 


\section{La felicidad como laetitia}

En cuanto la verdadera felicidad está basada en una visión de la realidad completa, ésta incluye sin duda alguna el sufrimiento. La persona feliz ya se relaciona de una manera determinada con el sufrimiento anterior al relevante juicio de valor (Werturteil) fundamentándolo. Quien es feliz ante la realidad que se manifiesta para él, ciertamente no huye del sufrimiento y, por ende, no niega su existencia real ni su significado. Por otra parte, tampoco se deja absorber por el sufrimiento, afirmándolo como la única realidad. Más bien, a través de su participación en la comunión y para llevar la felicidad a su plenitud, intenta vivir con veracidad el sufrimiento. Si es la misma persona quien sufre, ofrece la verdad que se revela dentro de la vivencia del dolor, para enriquecer y hacer más autentica la relación con sus seres queridos, puesto que su acercamiento a ellos está marcado por lo que vive. Huyendo a la soledad, que aparece como un posible modo de vivir dentro de cada sufrimiento, uno pierde el sentido verdadero de su vivencia, de la misma manera que también apartándose de la realidad plena puede perder de vista a las personas para quienes su sufrimiento sería una enseñanza y un ejemplo. Si es otra persona quien sufre, tampoco puede dar la espalda, puesto que es justamente aquí donde el sentido de la dificultad se desvanece, donde se encuentra la persona de un modo radicalmente nuevo: quien no conoce a sus amigos a la hora de sufrir, no los conoce bien. La felicidad implica por lo tanto adentrarse siempre en el sufrimiento. La felicidad que nos llena gracias a la experiencia de formar parte de una comunidad, asigna el último horizonte de comprensión, en el que puede aparecer el sentido del sufrimiento. Por ello la felicidad, cuando llega a su plenitud, se convierte en laetitia.

Veamos qué significa la felicidad como laetitia con respecto a la actitud frente al sufrimiento. En esta relación compleja se pueden distinguir diversas fases, que hasta cierto punto siguen la una a la otra, aproximándose al descubrimiento que se resume en la frase: In "laetitia”, nulla dies sine Cruce. (Cfr. Vázquez de Prada, 2003: p.21).

Con respecto al sufrimiento y en tanto estado del alma, la felicidad es verdaderamente una actividad, que llega a su plenitud y 
se manifiesta a través de diversos actos. Para escoger la dirección principal, es importante en este punto de nuestra meditación hacer hincapié en que - hablando en el nivel teológico- la persona feliz vive el sufrimiento a la luz de la salvación. Sólo nos acercan al verdadero sentido del sufrimiento tales experiencias de la comunión, que transmiten dos aspectos al mismo tiempo: la pequeñez de la persona y una confianza bien fundada y verificada en algo mayor e infinitamente más noble que ella que, a su vez, por el amor transmitido, le puede ayudar a perfeccionarse. En cuanto la communio personarum es capaz de transmitir este amor, que requiere un crecimiento personal a la hora de la miseria vivida, puede dilucidar el sentido del sufrimiento existencial.

Para todas aquellas personas que se sienten felices, el desafío más grande consiste ciertamente en enfrentarse con el sufrimiento; esta experiencia es, a menudo, la prueba de la autenticidad de la felicidad. El primer peldaño, el primer acto relevante, es el reconocimiento del sufrimiento como tal. Luego sigue el indagar y aclarar el sentido del sufrimiento, el análisis existencial del acontecimiento que nos ha hecho sufrir. Quien se pregunta por la esencia del sufrimiento en este contexto, no se interesa tanto por el hecho, por qué sufre, por qué le ha tocado a él, ni siquiera para qué sufre, sino que quiere entender su sufrimiento dentro de la relación más fundamental en la cual aparece. Ésta es la pregunta que remite y posibilita el descubrimiento existencial según el cual el sufrimiento sólo se revela en su naturaleza plena en la relación Dios-hombre. Ésta es la pregunta que nos permite poner en el centro de atención la "experiencia de la comunión"; a saber: es justamente aquí donde surgen las respuestas al sufrimiento que van incluso más allá de la dimensión sapiencial. Entre sufrimiento y sufrimiento hay mucha diferencia; de todas ellas, sin embargo, destaca la oposición clara entre el sufrimiento compartido y el sufrimiento que nos encierra en la soledad.

La aceptación del sufrimiento nunca es fácil; la resignación, sin embargo, es radicalmente insuficiente para la felicidad, sólo asegura un equilibrio del alma ciertamente muy frágil. La persona feliz tiene que estar dispuesta incluso a vivir el sufrimiento, tiene que asumir la Cruz, puesto que sólo así, con la Cruz sobre de sus hombros, puede 
mirar sin miedo a la realidad como un don, como un regalo. Aunque para un cierto racionalismo puede resultar sorprendente, si la Cruz no le da el equilibrio, su paseo se vuelve inseguro a cada paso, lo que implica un dolor, por pequeño que sea.

La persona que acepta y es capaz de vivir el sufrimiento puede decir: "Domine Deus in simplicitante cordis mei laetus obtuli universa: et populum tuum vidi con ingentigaudio tibi offerre donaria. Domine Deus, custodi hanc voluntatem cordis eurum". ${ }^{14}$

Del acto de la comprensión y de vivir el sufrimiento surge el ofrecimiento de él. La cita anterior también vislumbra cómo se entrelazan la actividad privada y comunitaria en este punto en la experiencia de lo divino.

El siguiente paso, la búsqueda del sufrimiento expiatorio, se relaciona con los anteriores de manera muy diferente, puesto que presupone una experiencia especial, una unidad con Dios radicalmente más estrecha. A esta unidad se refiere Cristo cuando en la víspera de su sufrimiento habla de la felicidad a sus discípulos: "Os he hablado de esto, para que mi alegría esté con vosotros, y vuestra alegría llegue a plenitud" (Jn 15,11).

Santa Benedicta de la Cruz (Edith Stein) lo formula así:

Es el voluntario sufrimiento expiatorio el que verdadera y realmente nos une íntimamente con el Señor. Cuando aparece, viene de una relación ya existente con Cristo, puesto que por naturaleza la persona evita el sufrimiento.Y la manía de sufrir causada por un deleite perverso en el dolor es algo completamente diferente del deseo de sufrir en la expiación. Tal gozo no es una aspiración espiritual, sino un deseo sensitivo, que no es mejor que cualquier deseo sensitivo. De hecho, es peor, porque va contra la naturaleza. Sólo alguien cuyos ojos espirituales se han abierto a la correlación sobrenatural de los eventos mundanos puede desear sufrir en la

14 "Con la sencillez de mi corazón alegre te he ofrecido todo y así he visto a tu pueblo ofrecerte dones con gran alegría". Oración de ofertorio de la antigua liturgia de la fiesta del Sagrado Corazón de Jésus (Messale Ambrosiano, p.225). Véase también la interpretación de 1Cor 29, 17-18 de Luigi Giussani (1999, p.164). 
expiación, y esto solo es posible para personas en quienes habita el espíritu de Cristo, aquellos a los que, como miembros, les es dada la vida por el Señor, reciben su poder, su sentido y su dirección. Al contrario, las obras de expiación unen más estrechamente a Cristo, al igual que toda comunidad que trabaja junta en una tarea se apiña, y del mismo modo que los miembros de un cuerpo, trabajando juntos orgánicamente, se hacen uno de manera creciente... "el amor a la cruz de ninguna manera contradice el hecho de ser un feliz hijo de Dios". Ayudar a Cristo a llevar su Cruz le llena a uno de una alegría fuerte y pura, y quien quiere y puede hacerlo — los trabajadores del reino de Dios — son los más auténticos hijos de Dios... Sólo en unión con la cabeza divina el sufrimiento adquiere poder expiatorio (2002: p.130). ${ }^{15}$

15 La tradución es mía. 


\section{REFERENCIAS}

Messale Ambrosiano, della Pasque all'Avvento. Milán, 1942.

Aristóteles, Ética a Nicómaco. Madrid, Editorial Gredos.

Bernardo de Claraval. 1999. En la escuela del amor. Madrid, Biblioteca de Autores Cristianos.

CAldera, Rafael Tomás. 2010. El oficio del sabio. Madrid, Ediciones Internacionales Universitarias, D.L.

Crespo, Mariano. 2007. "Esbozo de una fenomenología de las disposiciones de ánimo" en Dialogo Filosófico, n.68, Mayo/Agosto.

Foucault, Michel. 1994. Dits at érits, I-IV. Paris, Gallimard.

Giussani, Luigi. 1999. Crear huellas en la historia del mundo. Madrid, Ediciones Encuentro.

Gregorio De Niza. 2009. Dogmatic Treatises. Edinburgh, T\&T Clark, under the editorial supervision of Philip Schaff, D.D., LL.D.

Grygiel, Stanislaw. 2002. Extra comunionem personarum nulla philosophia. Prolusione Dies Academicus 2001-2002, Roma, Lateran University Press.

Наdoт, Pierre. 1987. Exercises spirituels et philosophie antique. Paris, Études Augustiniennes.

Hildebrand, Dietrich. 1971. DasWesen der Liebe. Regensburg, Josef Habbel Verlag.

Husserl, Edmund. 1929. Cartesianische Meditationen und Parisier Vorträge, Husserliana I. The Hague, Martinus Nijhoff, 1973.

Husserl, Edmund. 1936. Die Krisis der europäischenWissenschaften und die Transzendentale Phänomenologie (HusserlianaVI), The Hague, Martinus Nijhoff, 1976.

Marcel, Gabriel. 1935. Être et avoir. Paris, Fernand Aubier, Éditions Mantaigne.

Marcel, Gabriel. 1959. Présence et immortalité. Paris, Flammarion.

Martin, L.H. et. al. 1988. Technologies of the Self: A Seminar with Michel Foucault. London, Tavistock.

Nemesio de Emesa. 1975. De natura hominis, Leiden, Brill. Traducción de Burgundio de Pisa.

Patocka, Jan. 1996. Heretical Essays in the Philosophy of History (Kacírské eseje o filosofii dêjin) (Edited by James Dodd). Chicago, Open Court. Translated by Erazim Kohák.

Pico de la Mirandola, G. 1984. De la dignidad del hombre. Madrid. Editoria Nacional. Platón, Diálogos y cartas (varios tomos). Madrid, Editorial Gredos. 
Reinach, Adolf. 1951. Was ist Phänomenologie? München, Kösel Verlag.

SeIFerT, Josef. 1977. Back to Things in Themselves: A Phenomenological Foundation for Classical Realism. New York, Routledge and Kegan Paul.

Stein, Edith. 2002. Essential Writings (ed. John Sullivan O.C.D.) New York, Orbis Books.

Szalay, Mátyás. 2008. "Spiritual Friendship and the Foundations of Political Community” en Joanna Nowick y Czeslaw Porebski (ed.) L'Invention de l'Autre, Paris, Sandre.

VÁzquez de Prada, Andrés. 2003. The Founder of Opus Dei, The Life of Josemaría Escrivá. (Volume II: God and daring), New York. 